\title{
Efficacy of Sitagliptin Versus Glimepiride 1-3 mg for Treatment of Type-2 Diabetes Patients
}

\author{
Bhaskar Joshi', Praveen Yadav, Annabathini Geetha Bhavani ${ }^{1,2, *}$ \\ 'Department of Chemistry, Noida International University, Gautama Buddha Nagar, Greater Noida, Uttar Pradesh-203201, INDIA. \\ ${ }^{2}$ Noida International University Research Innovation Centre, Noida International University, Gautama Buddha Nagar, Greater Noida-203201, Uttar Pradesh, INDIA.
}

\begin{abstract}
Objectives: This study is to compare the effect of Sitagliptin and Glimepiride 1-3mg as a combination therapy for type-2 diabetes mellitus patient's treatment. It is also concern to evaluate the effect of low dosage on type-2 diabetes mellitus patients as an antidiabetic drug. Methods: The type-2 diabetes patient's clinical data was analyzed during the treatment through the inclusion and exclusion selection methods. The samples of Sitagliptin (1-3 mg) as add on therapy were chosen by open label study by randomization on type- 2 diabetes mellitus. The total 45 patients $(n=45)$ with age group between $20-60$ years was received for statistical analysis. The samples are screened by inclusion with the baseline of HBA1c was $\geq 7.0 \%$ and $\leq 10.5 \%$ was selected. The exclusion criteria are restricted to upper age limit of 60 years and having the symptoms of chronic kidney, hepatic, malignancy. Results: The data of combination therapy is compared with initial data and after 14 weeks of treatment data is considered for the effect of antidiabetic drugs. The statistic results show with greater improvement in $\mathrm{HbA} 1 \mathrm{c}$ value and total daily dose of insulin were achieved with Sitagliptin
\end{abstract}

compared to Glimepiride therapy. Concluscion: Finally, Sitagliptin 100mg is an add-on to Metformin treatment shows more adequate results with better tolerance on type-2 diabetes with satisfactory glycemic control is found to be significant reduction with daily dose of insulin in the body. Key words: Efficacy, Sitagliptin, Glimepiride1-3mg, HbA 1 value, Type-2 diabetes mellitus.

\section{Correspondence}

\section{Dr. A Geetha Bhavani}

'Department of Chemistry, Noida International University, Gautama Buddha Nagar, Greater Noida, Uttar Pradesh-203201, INDIA.

${ }^{2}$ Noida International University Research Innovation Centre, Noida International University, Gautama Buddha Nagar, Greater Noida-203201, Uttar Pradesh, INDIA. Phone no: +918826699428

Email: ageethabhavani@gmail.com

DOI: 10.5330/ijpi.2020.4.103

\section{INTRODUCTION}

Type-2 diabetes mellitus (T2DM) is found to be silently chronicle and numbers are increasing day by day globally. The world health organization estimates 415 million patients with T2DM globally, which may escalate to 642 million by $2040 .{ }^{1} \mathrm{~T} 2 \mathrm{DM}$ is characterized by elevated plasma glucose levels, blood glucose fasting, blood sugar post prandial and glycosylated hemoglobin and type-2 diabetes (T2D) accounts for most patients associated with diabetes mellitus. The risk of acquiring $\mathrm{T} 2 \mathrm{D}$ is determined by a combination of environmental factors and genetic susceptibility. The T2DM is well known treatment with both oral and injectable, among oral drugs well prescribed as a painless and equally effective.

Metformin is the first-line of treatment for type-2 diabetes mellitus patients. Metformin and sulfonylureas (SU) is the commonly used oral antidiabetic agents and mostly physician start with first line of treatment to ensure the patient is diabetic or non-diabetic. However, few side effects are noticed with SU drugs subjection are multiple changes like increase hypoglycaemia and weight gain. The physicians do not recommend the usage of SU drugs as they are associated with many limitations. The combination therapy is well practiced as they do not evident any side effects on patients and patients will ultimately require to be shifted to another class of oral antidiabetic agents or insulin therapy. ${ }^{2,3}$ The class of oral antidiabetic drugs also DPP-4 inhibitors to enhance function of endogenous incretin and helps with glucose homoeostasis without increasing the risk of hypoglycaemia and weight gain ${ }^{4,5}$ due to the multiple action on Sitagliptin such as anti-inflammatory, effect on monocytes and T-lymphocytes are the clinical usefulness of the addition of Sitagliptin in T2DM could beyond glycemic reduction. The secondary effects like prevention of weight gain, may be expected from the addition of Sitagliptin to diabetes treatment. ${ }^{6,7}$ This study was made to evaluate the medication like Metformin and Sitagliptin over the T2DM patients through statistical analysis.

\section{METHODOLOGY}

This study deign was on open label system on enrolled T2DM patients in the duration of $1^{\text {st }}$ September 2017 to $30^{\text {th }}$ September 2019 in Felix Hospital, Noida, U.P. India. The ethical committee was approved to analyze the patients undergoing the treatments for T2DM with registration number of NERB/SOS/CHEM/18/106 from patients data stored in hospital records (supporting information). All the T2DM patients are given the written consent for data analysis and results publication (supporting information).

The main subjects of study were gender specific and age between 20 to 60 years or older group with passable monitored glucose level by glycosylated hemoglobin (HbA1c) test of $\geq 7.0 \%$ and $\leq 10.5 \%$. After $14^{\text {th }}$ weeks of treatment with Sitagliptin and Glimepiride on T2DM patients, the $\mathrm{HbA}_{1 \mathrm{c}}$ was monitored and compared with previous results. Figure 1 represents the flowchart of present study on effect of Sitagliptin and Glimepiride on T2DM patients. For this study the data of T2DM patients with symptoms of (i) any history of ketosis, (ii) any surgical treatment for severe infections, (iii) any symptoms of renal disease (serum creatinine level $>1.6 \mathrm{mg} / \mathrm{dl}$ ), (iv) any history with malignancy and hepatic and (v) any history of allergy or pregnancy was excluded. ${ }^{7,8}$ The statistical analysis based on numerical data collected with patients' drug treatments. The 
chi-square test was used to analyze the patient's data and perform the ' $p$ ' test. SD and Mean calculated by mathematical formulas and level of significance analyzed by null hypothesis. The prepared database was shown in Table 1 with calculation of Mean, SD (stander deviation) and ' $p$ ' values to interrupt with accuracy. The study initial phase the patients has shown high HBA1c level and blood sugar level. Over the period of 14 weeks of medication with sitagliptin the $\mathrm{HBA}_{1 \mathrm{c}}$ level and blood glucose level was found to be considerably decreased, which show significant effect of medication.

\section{RESULTS}

The present study is to observe the clinical data of T2DM patients to evaluate the effects of combination therapy (Metformin and Sitagliptin of $100 \mathrm{mg}$ dosage over Metformin). The blood samples are analyzed to find the effect of combination therapy consequences on variables like patient glycemic control and BMI is monitored and listed (supplementary data) over age groups of 20-60 years, which includes both male and female patients. The analysis data of Sitagliptin and Metformin treatment were compared in Table 1 and 2 and Figure 2-4, respectively.

The patients data is segregated on the basis of $\mathrm{HbA}_{1 \mathrm{c}}$ parameter as blood sugar levels is substantial in most of the people and also fluctuate with their physiological conditions, stress level and composition of the meal. The HbA1c level is $\geq 7.0 \%-\leq 10.5 \%$ is consider as the baseline for selection of the diabetic patients data. The empirical data to test the hypothesis for significant difference between the effect of Sitagliptin with Metformin combination and Glimepiride drugs to treat diabetes, which are recognized anti-hyperglycemic effect. The total 45 patient's samples are selected to assess the treatment effects. In that 29 samples data were selected according to inclusion method and 16 were selected according to exclusion method with using $\mathrm{HbA}_{1 c}$ parameter as baseline. The 29 patients data were again segregated into two groups, one group

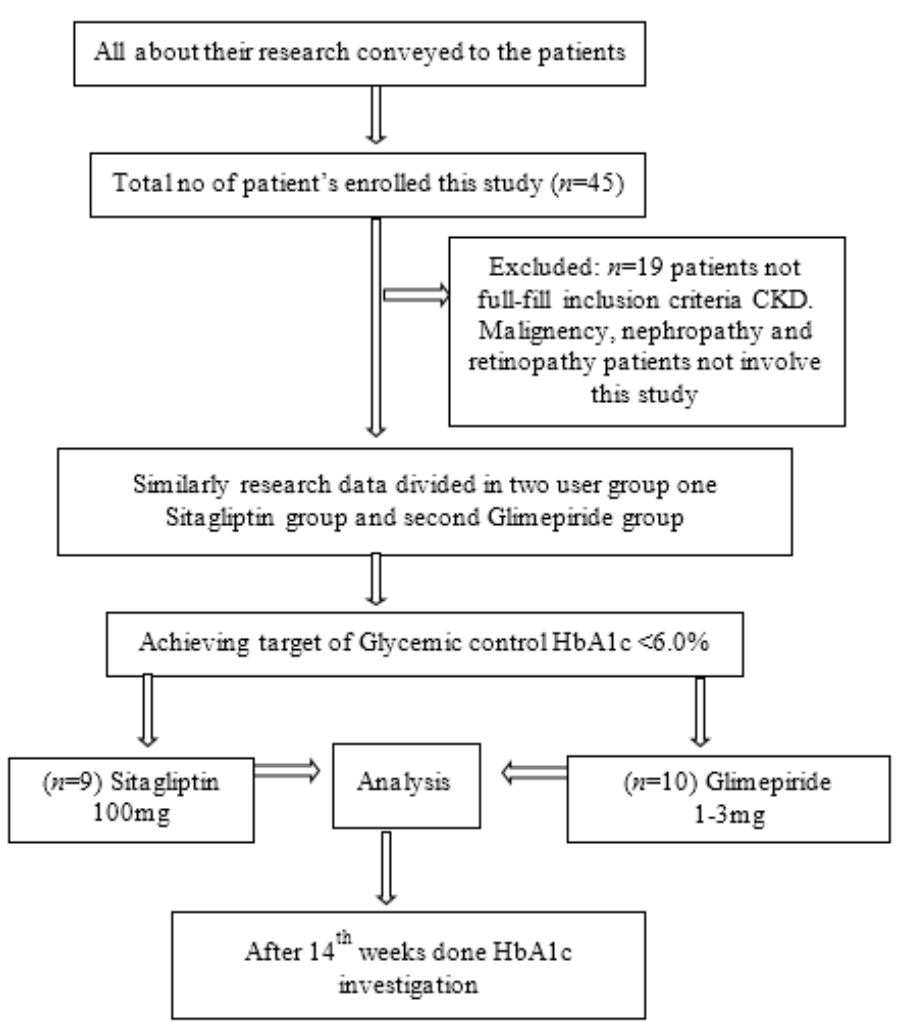

Figure 1: Flow chart of methodology of sample analysis of Sitagliptin and Glimepiride effect on T2DM patients. received treatment of Sitagliptin (100mg) with 19 number of patients $(n=19)$ and another group received treatment with Glimepiride (1-3mg) with 10 number of patients $(n=10)$. The mean and standard deviations of these groups are shown in Table 1 . The hypothesis is tested by finding the probability value (' $p$ ' value) to analyze the obtained results. The level of significance is taken as $5 \%$ (The smaller ' $p$ ' value $(<0.05)$ indicates the strong evidence against the null hypothesis and larger ' $p$ ' value $(>0.05)$ indicates the weak evidence against to fail or reject the null hypothesis.

The ' $p$ ' value of chi square test indicates that the test with no significant difference in the effect of the drug among the gender. In the other words these drugs are equally efficient among male and female. The mean value of the analysis with Sitagliptin $(100 \mathrm{mg}$ ) treatment has come out with 8.86 and standard deviation is found to be 2.15. The ' $p$ ' value of chi square test is resulted as 0.99 . The treatment with Glimepiride $(1-3 \mathrm{mg})$ shows the mean and standard deviation values are found to be 8.47 and 1.90 with the ' $p$ ' value of chi square test of 0.99 value is obtained. The $\mathrm{Hb}$ data of Sitagliptin treatment shows the mean and SD values are found to be 11.1 and 3.44, which are quiet significant. The $\mathrm{Hb}$ data of Glimepiride treated samples shows the mean and SD values are found to be 11.91 and SD 2.24. The ' $p$ ' value of 0.73 is noticed for both Sitagliptin and Glimepiride treated patients. The ' $t$ ' test analysis indicates the significant difference in the Sitagliptin and Glimepiride effectiveness, which is due to the patients age. Table 1 shows Sitagliptin works efficiently compared to Glimepiride usage with irrespective of age groups. The comparative data shows significant change in both $\mathrm{Hb}$ and BMI parameters on both the drug treatments. The $\mathrm{HbA}_{1 \mathrm{c}}$ parameter shows equal efficiency by both the drugs on male and female patients. The data were compared between the two groups using unpaired ' $t$ ' test. The one group data measured the

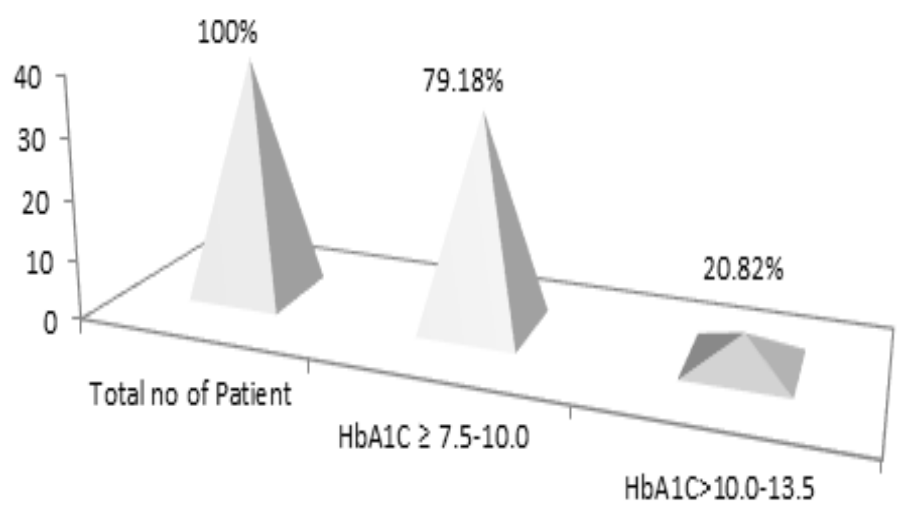

Figure 2: Comparative study of $\mathrm{HbA}_{1 \mathrm{c}}$ result with number of patients.

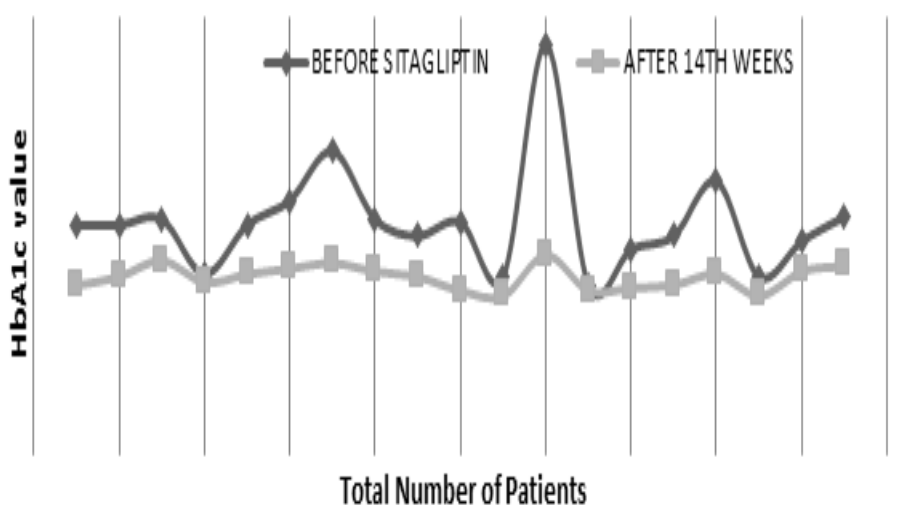

Figure 3: Graphical presentation of $\mathrm{HbA}_{1 \mathrm{c}}$ results of before and after treatment of Sitagliptin (100mg). 
' $p$ ' value is 0.99 indicates the patient required the insulin doses, where as another group shows the proportional test specifies the lower insulin doses requirement. Table 2 shows the results of repeated test on $\mathrm{HbA}_{1 \mathrm{c}}$ level tested after 14 weeks of treatment with Sitagliptin and Glimepiride. The 14 weeks of treatment data on $\mathrm{HbA}_{1 \mathrm{c}}$ level shows the significant drop down from baseline in comparison with initial values, which clears the positive effect of the treatment. The ANCOVA results show significant difference in the change in $\mathrm{HbA}_{1 c}$ with Sitagliptin and Glimepiride (' $p$ ' value is 1 ), with reduction in $\mathrm{HbA}_{1 c}$ seen with Sitagliptin regimen compared to Glimepiride regimen. However, there was a promising effect on the $\mathrm{HbA}_{1 \mathrm{c}}$ level after 14 weeks of treatment and attained target of $\mathrm{HbAlc}$ with $<7.0 \%$ by Sitagliptin compare to Glimepiride therapy. The insulin secretion is clearly depends on dipeptidyl peptidase-4 (DPP4) enzyme with glycogen like peptide-1(GLP-1) in pancreatic beta cells, which effects the $\mathrm{HbA}_{1 \mathrm{c}}$ level in blood. The medication with Sitagliptin inhibits the DPP-4 enzyme and enhances the insulin release from the body through GLP-1 incretin. This process with due courses of treatment lowers the insulin and the blood glucose level in blood. The continuous treatment with sitagliptin the glycosylated hemoglobin level also lower down without increasing the body weight, postprandial level and lipid profile level was also found in enrolled patients.

Figure 2, revels the comparison of total number of 45 patients with $\mathrm{HbA}_{1 \mathrm{c}}$ $\geq 7.5 \%-10.0 \%$ patients of $29(n=29)$ and $\mathrm{HbA}_{1 c}>10.0 \%-13.5 \%$ patients of $16(n=16)$. Among the patients with the average BMI is found to be 21.20 and SD of 4.42 with the ' $p$ ' value of 0.59 . The Figure 3, signifies the two different variables of (i) first one is before the treatment with Sitagliptin and (ii) second one is after 14 weeks treatment with Sitagliptin. The test results confirm the insulin and Glimepiride combination therapy significantly affects the glycemic controls with proficiency. The Figure 4 shows number of patient's data analysis with two variables like (i)

Table 2: $\mathbf{H b A}_{1 \mathrm{c}}(\%)$ value change from dataset.

\begin{tabular}{cccccccc} 
& \multicolumn{3}{c}{$\begin{array}{c}\text { Sitagliptin(100mg) } \\
(n=19)\end{array}$} & & \multicolumn{4}{c}{$\begin{array}{c}\text { Glimepiride(1-3mg) } \\
(n=10)\end{array}$} & $\begin{array}{c}\text { ' } p \text { ' } \\
\text { value }\end{array}$ \\
\hline & $\mathrm{n}$ & Mean & s.d & $\mathrm{N}$ & Mean & s.d & \\
\hline $\mathrm{HbA}_{1 \mathrm{C}}$ Value & 19 & 6.48 & 0.44 & 10 & 7.09 & 0.64 & \\
Gender/Male & 10 & 6.52 & 0.64 & 05 & 6.92 & 0.81 & 1 \\
$\begin{array}{c}\text { Gender/ } \\
\text { Female }\end{array}$ & 09 & 6.38 & 0.42 & 05 & 7.26 & 0.45 & \\
\hline
\end{tabular}

All values for $\mathrm{HbA}_{1 \mathrm{c}}$ expressed in \%.

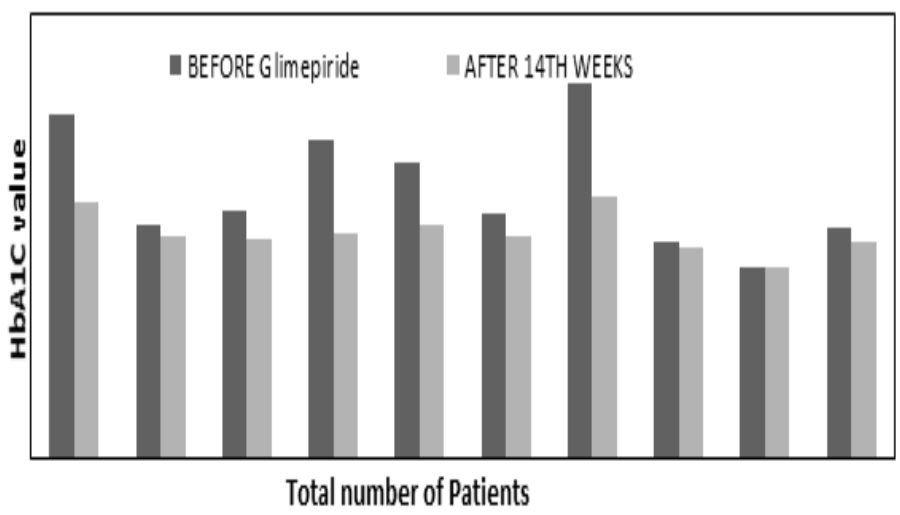

Figure 4: The Effects of before treatment and after treatment of Glimepiride on patients. before treatment with Glimepiride (ii) after 14 weeks treatment with Glimepiride.

\section{DISCUSSION}

The results of present study showed the drug has a considerable effect on the glycemic control of all the patients. The 14 weeks treatment over Sitagliptin $(100 \mathrm{mg})$ shows promising results on diabetic patients compared with the Glimepiride. The earlier report on effect of Glimepiride (1-3 mg) over on type-2 diabetes patients treatment with a duration of 14 weeks shows a major risk factor for developing both microvascular and macrovascular complication. ${ }^{9}$ The primary goal of $\mathrm{T} 2 \mathrm{DM}$ treatment is to target glycemic control by maintaining the $\mathrm{HbA}_{1 \mathrm{c}}$ level nearly 6 to $7 \%$ in order to decrease the incidence of microvascular and macrovascular complications without predisposing patients to hypoglycemia. ${ }^{10}$ Unless diabetes remains uncontrolled with first-line therapy, medication including insulin, SU, thiazolidediones (TZDs), GLP-1analogs or gliflozins are also employed in combinations. ${ }^{11}$

Administration of TZDs drugs increases the risk of fracture and cardiac failure, whereas SU drugs are losing their effectiveness over time. The recent report reveals the approach of target the incretion mimetic hormone GLP-1 and GLP-1 release are the responsible to hyperglycemia (diabetes mellitus) and stimulates the insulin secretion by decreasing glucagon secretion. Further improves beta-cell functioning and slowing the gastric emptying. Usually GLP-1 production is reduced in patients with T2DM. On other hand GLP-1 is produced and rapidly degraded by DPP- $4,{ }^{12}$ which could be due to genetic factors leads the possibility of insulin deficiency. The reports also confirms the DPP-4 inhibitors also found to be lowering humiliation of glucagon like peptides in the body. ${ }^{13-15}$ The statistical data for conducting the required test for this study suggest that the Sitagliptin with Metformin is more effective for the treatment of hyperglycemia compare than Glimepiride. A recent study on diabetes mellitus type-2 treatment with Sitagliptin also shows effectively reduces $\mathrm{HbA}_{1 \mathrm{c}}$ and more significantly decrease in HbAlc level by add-on with Sitagliptin. ${ }^{16}$ Metformin as an add-on therapy with Sitagliptin is found to be controlled levels of glycemic over type2 patients ${ }^{17}$ and indicates low risk with control of hypoglycemia. The dose of Sitagliptin (100mg) is higher than Glimepiride (1-3 mg) leads effective control the level of sugar, insulin. The T2DM patients shown the reducing number of beta cell in pancreas, which also confirmed ${ }^{18}$ by the experiment on animal with treatment of Sitagliptin found the

Table 1: Data of Sitagliptin (100mg) and Glimepiride (1-3mg). *

\begin{tabular}{|c|c|c|c|}
\hline \multicolumn{4}{|c|}{ Chi square Test } \\
\hline & $\begin{array}{c}\text { Sitagliptin } \\
(100 \mathrm{mg})(n=19) \\
\text { No. (\%) Mean(S.D) }\end{array}$ & $\begin{array}{l}\text { Glimepiride (1- } \\
\text { 3mg) }(n=10) \text { No. } \\
\text { (\%) Mean(S.D) }\end{array}$ & $\begin{array}{l}\text { Chi Square } \\
\text { Statistic' } p \\
\text { value' }\end{array}$ \\
\hline Gender/Male & $57.57(8.92)$ & $54.60(15.61)$ & 0.13 \\
\hline \multirow{2}{*}{$\begin{array}{l}\text { Gender/ } \\
\text { Female }\end{array}$} & $52.43(9.18)$ & $52.60(13.20)$ & - \\
\hline & & & $\begin{array}{c}\text { ' } t \text { ' statistic ' } p \text { ' } \\
\text { value }\end{array}$ \\
\hline Age (years) & $51.11(8.69)$ & $53.60(13.67)$ & 0.01298271 \\
\hline $\begin{array}{l}\text { BMI (kg/ } \\
\text { sq.m) }\end{array}$ & $20.22(3.55)$ & $23.05(5.44)$ & 0.59 \\
\hline $\mathrm{Hb}(\mathrm{g} \%)$ & $11.1(3.44)$ & $11.91(2.24)$ & 0.73 \\
\hline $\begin{array}{l}\text { During of } \\
\text { DM HbA }_{1 c} \\
\quad(\%)\end{array}$ & $8.86(2.15)$ & $8.47(1.90)$ & 0.99 \\
\hline
\end{tabular}


pancreatic beta cell are been protecting by growth promoting effect. Our present study also supports pancreatic beta cell protecting activity with the medications of Sitagliptin. In nutshell patients data analysis shows Sitagliptin with Metformin control the glycemia more effectively compare than Glimepiride.

\section{CONCLUSION}

Sitagliptin add-on metformin treatment was more efficiency and very good tolerated in type-2 diabetes mellitus in adequate glycemic control significant reduction in total daily dose of the insulin required in body. Compared to initial phase $\mathrm{HBA}_{1 \mathrm{c}}$ and blood glucose level was found to be reduced significantly with the medication of Sitagliptin in due course of time duration. Sitagliptin (100mg) when compared to glimepiride (1-3mg) more than effectively to T2DM patients in terms of achieving greater glycemic control and most significant reduction in total daily dose required in insulin.

\section{ACKNOWLEDGEMENT}

The authors would like to express our gratitude to Ethical Committee members Prof. Jayanand and Dr. Varun Kumar Sharma of Noida International University Research and Innovations Centre for approving the present study. We also thank to Dr. D.K. Gupta, Chairman of Felix hospital Noida, Dr. Shilpi Gupta, Department of Microbiology, School of Science, Amity University, Mr. Ravi Prakash Maurya, Ms. Sweeti Kushwaha, Department of Pathology, Felix hospital Noida, for there valuable guidance during the manuscript revision.

\section{CONFLICT OF INTEREST}

The authors declare that they have no conflict of interest. The authors are responsible for the content and writing of this article.

\section{ABBREVIATIONS}

T2DM: Type-2 Diabetes Mellitus; DM: Diabetes Mellitus; T2D: Type2 Diabetes; SU: Sulfonylureas; BMI: Body Mass Index; HbA $\mathbf{A c}_{\mathbf{c}}$ : The hemoglobin A1c test shows the average level of blood sugar over the past 2 to 3 months; TZDs: Thiazolidediones; GLP-1: Glucagon-like Peptide-1; DPP-4: Dipeptidyl peptidase 4.

\section{REFERENCES}

1. Kirpichnikov D, McFarlane SI, Sowers JR. Metformin: An update. Ann Intern Med. 2002;137(1):25-33.

2. Reichard P, Berglund B, Britz A, Cars I, Nilsson, Rosenqvist U. Intensive bloodglucose control with sulphonylureas or insulin compared with conventional treatment and risk of complications in patients with type-2 diabetes (UKPDS 33): UK Prospective Diabetes Study (UKPDS) Group. Lancet. 1998;352(9131):83743.

3. Zimmerman BR. Sulfonylureas. Endocrinol Metab Clin North Am. 1997;26(3):511-2.

4. Mulvihill EE, Drucker DJ. Pharmacology, physiology and mechanisms of action of dipeptidyl peptidase-4 inhibitors. Endocrine Rev. 2014;35(6):992-9.

5. Lindenmeyer A. Interventions to improve adherence to medication in people with type-2 diabetes mellitus: A review of the literature on the role of pharmacists. J Clin Pharm Therapeutics. 2006;31(5):409-9.

6. Scheen AJ. Cardiovascular effect of Sitagliptin. Nat Rev Cardiol. 2013;10:73-4.

7. Kerr D, Phillip M. Improved glycemic control in poorly controlled patients with type 1 diabetes using real-time continuous glucose monitoring. Diabetes Care. 2006;29(12):2730-2.

8. Avogaro A, Fadini GP. The effects of dipeptodyl peptidase-4 inhibition on microvascular diabetes complications. Diabetes Care. 2014;37(10):2884-4.

9. Rury RH, Sanjoy KP, Angelyn BM, David RM, Andrew WN. 10-Year Follow-up of intensive glucose control in type 2 diabetes. NEJM. 2008;359(15):1577-9.

10. Choy M, Lam S. Sitagliptin: A novel drug for the treatment of type-2 diabetes. Cardiol Rev. 2007;15(5):264-71.

11. Inzucchi SE, Bergenstal RM, Buse JB, Diamant M, Ferrannini E, Nauck M, et al. Management of hyperglycemia in type 2 diabetes: A patient-centered approach: Update to a position statement of the American Diabetes Association and the European Association for the Study of Diabetes. Diabetes Care. 2015;38(1):1409.

12. Nissen SE, Wolski K. Effect of rosiglitazone on the risk of myocardial infarction and death from cardiovascular causes. NEJM. 2007;356(24):2457-1.

13. Shi C, Zhang R, Bai R, Liu D, Wang Y, Zhang $X$, et al. Efficacy and safety of sitagliptin added to metformin and insulin compared with voglibose in patients with newly diagnosed type-2 diabetes. Clinics. 2019;74:e736.

14. Bae EJ. Dipeptidyl peptidase-IV inhibitors in diabetes complication: role of DDP4 beyond glucose control. Arch Pharm. 2016;39(8):1114-8.

15. Idris I, Donnelly R. Dipeptidyl peptidase-IV inhibitors: A major new class of oral antidiabetic drug. Diabetes Obes Metab. 2007;9(2):153-5.

16. Sato S, Saisho Y, Kou K, Meguro S, Tanaka M, Irie J. Efficacy and safety of sitagliptin added to insulin in Janpanes patients with type-2 diabetes. PloS one. 2015;10(3):e0121988

17. Pasquel PJ, Gianchandani R, Rubin DJ. Efficacy of Sitagliptin for the hospital management of general medicine and surgery patients with type-2 diabetes. Lancet Diabetes Endocrinol. 2017;5(2):125-3.

18. Shi $C$, Zhang $R$, Bai $R$, Liu D, Wang $Y$, Zhang $X$, et al. Efficacy and safety of sitagliptin added to metformin and insulin compared with voglibose in patients with newly diagnosed type 2 diabetes. Clinics. 2019;74:e736.

Article History: Submission Date : 17-09-2020; Revised Date : 05-08-2020; Acceptance Date : 25-10-2020.

Cite this article: Joshi B, Yadav P, Bhavani AG. Efficacy of Sitagliptin Versus Glimepiride 1-3mg for Treatment of Type-2 Diabetes Patients. Int. J. Pharm. Investigation, 2020;10(4):590-3. 